\title{
Marfan's syndrome and isolated aneurysm of the abdominal aorta
}

\author{
BART VAN OOIJEN
}

From the Department of Surgery, Bronovo Hospital, The Hague, The Netherlands

SUMMARY A 43 year old woman presented with an aneurysm of the abdominal aorta. Marfan's syndrome was diagnosed as the underlying cause of the aneurysm. An isolated aneurysm as presenting sign of Marfan's syndrome is rare. In a review of published reports about 30 cases were found.

Marfan's syndrome is a congenital disorder of connective tissue that can affect the skeleton, ${ }^{1}$ the eyes, ${ }^{2}$ and the cardiovascular system. ${ }^{3}$ The cardiovascular manifestations of this syndrome can be life threatening ${ }^{4}$; as a rule death is caused by aortic and mitral valve incompetence, aortic dissection, aneurysmal rupture, mural complications of an ascending aortic aneurysm, or subacute bacterial endocarditis. ${ }^{4}$

The aneurysm associated with Marfan's syndrome is usually localised in the ascending aorta, although it may be found at several other sites. An aneurysm of the abdominal aorta is, however, rare. ${ }^{4}$ In this report a patient presenting with an isolated infrarenal aneurysm of the abdominal aorta is described. She was successfully operated on, but in the follow up period other severe cardiovascular complications developed that led to sudden death five months after operation.

\section{Case report}

A 43 year old woman was admitted to hospital because of a continuous pain in the abdomen. The pain had developed suddenly in the week before admission. The intensity of pain in the umbilical region had increased. She had vomited once.

The patient was remarkably tall $(1.86 \mathrm{~m})$ and thin. Her blood pressure was $130 / 70 \mathrm{~mm} \mathrm{Hg}$ and the pulse rate was 100 beats per minute. The lungs were clear; there were no signs of cardiac failure. A pulsatile mass $6 \mathrm{~cm}$ in diameter was palpable in the midline of the abdomen. Findings suggestive of Mar-

Requests for reprints to Dr Bart van Ooijen, Department of Surgery, Bronovo Hospital, Bronovolaan 5, 2597 AX The Hague, The Netherlands. fan's syndrome were lumbar scoliosis and arachnodactyly.

Laboratory data were normal. An infrarenal aneurysm was demonstrated by ultrasonography and aortography (fig 1). The heart, mediastinum, and the thoracic aorta were normal on the chest $x$ ray as well as the conventional ultrasound scan in so far as assessment was possible.

At laparotomy an aneurysm $(8 \mathrm{~cm}$ long and $5 \mathrm{~cm}$ in diameter) was found; the calibre at the aortic

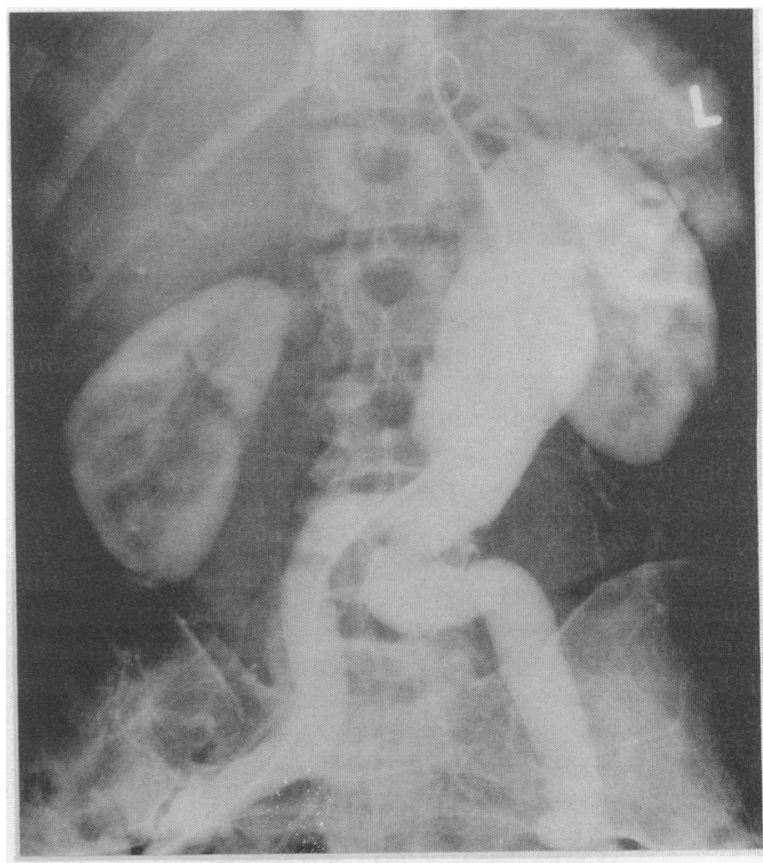

Fig 1 Aortogram showing an infrarenal aneurysm; the calibre at the aortic bifurcation is normal. 
bifurcation was normal, but the iliac arteries were slightly dilated. The affected segment of the aorta was replaced by a woven Dacron tubular graft.

Histological examination of the aneurysmal wall showed severe degeneration of the elastic fibres of the aortic tunica media and accumulation of mucopolysaccharides.

The postoperative course was uncomplicated; the patient was discharged 13 days after operation.

Four months later ultrasonography of the abdominal aorta and the graft showed no abnormalities. The rest of the aorta was not checked, however. Five months after the operation she was readmitted because of sudden chest pain and severe dyspnoea. Her blood pressure was $100 / 30 \mathrm{~mm} \mathrm{Hg}$ and the pulse rate was 120 beats per minute. On the chest $x$ ray the mediastinum was not enlarged. Ultrasonography of the abdominal aorta, however, showed a loose fragment in the proximal subdiaphragmatic segment, resembling the lower part of a dissecting thoracic aneurysm (fig 2). Operation was not attempted and she died soon after admission.

A postmortem examination showed a dissecting aneurysm attributable to a $4.5 \mathrm{~cm}$ tear in both the intima and the tunica media, starting approximately $1.5 \mathrm{~cm}$ above the aortic valves. The dissection extended into the left coronary artery and downwards to the level of the renal arteries and affected the left renal artery. There was severe pulmonary oedema; there were no obvious macroscopic changes in the heart and the area surrounding the aortic Dacron graft was normal. Histological examination of the aorta at the level of the dissection showed severe degeneration of the elastic fibres of the tunica media and accumulation of mucopolysaccharides.

\section{Discussion}

Marfan's syndrome is fairly readily diagnosed when the classic features are present, but formes frustes are difficult to detect and define. As a rule, all aspects of the syndrome are not expressed in one patient. This patient presented with an abdominal aortic aneurysm. She was not known to have Marfan's syndrome; the family history was negative, there were no ocular abnormalities and only a few skeletal features characteristic of Marfan's syndrome were present. According to Pyeritz and McKusick; however, two positive criteria are sufficient for the diagnosis. $^{5}$

An aneurysm of the elastic arteries is characteristic of the vascular manifestations of Marfan's syndrome. The aneurysm is frequently located in the ascending aorta; a concomitant weakness of the aortic ring almost always leads to aortic regurgitation. ${ }^{4}$ Aortic lesions tend to be the predominant sign in adults,${ }^{4}$ while mitral regurgitation is more common in children. ${ }^{6}$

There are twice as many elastic fibres in the ascending aorta as in the abdominal aorta. Since the ascending aorta is also subjected to pressure changes this might explain the frequent development of aneurysms in the ascending aorta. ${ }^{7}$ Moreover, this portion of the aorta has the largest diameter and, according to the law of Laplace, is therefore exposed to the greatest wall tension.

Though aneurysms may develop at a number of

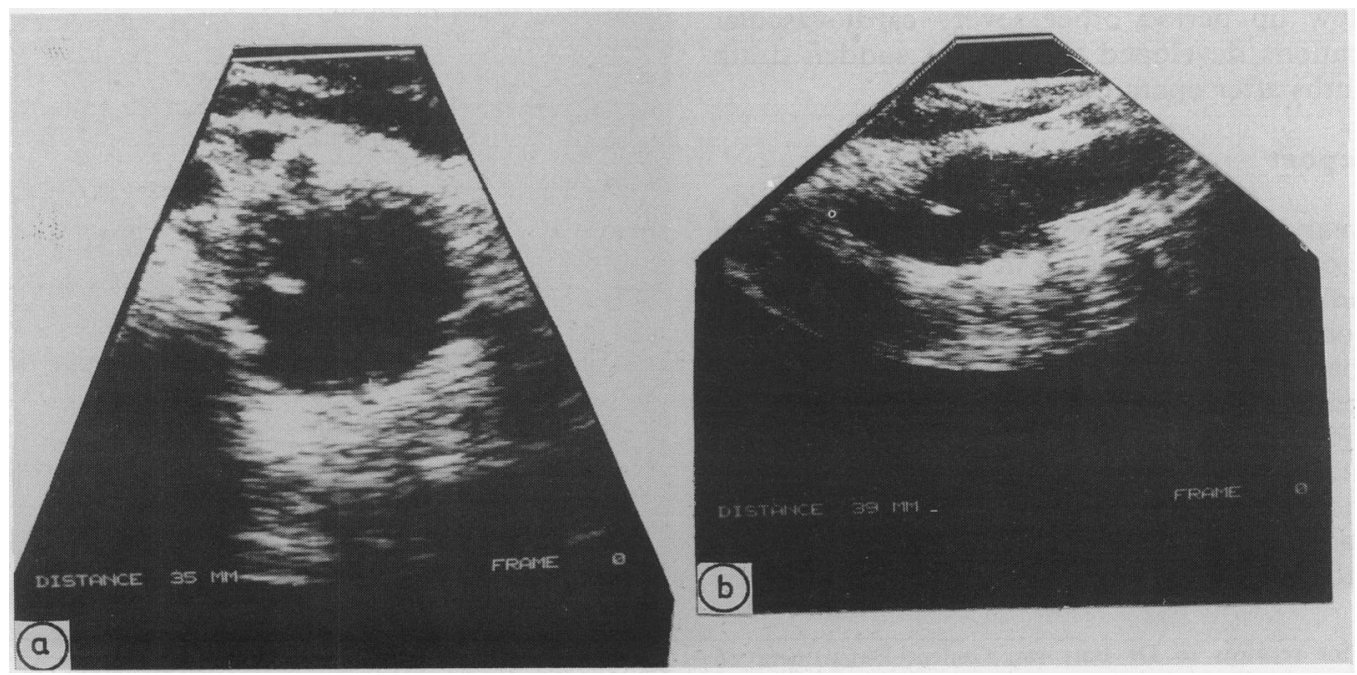

Fig 2 Ultrasonograms showing a dissection extending into the subdiaphragmatic segment of the abdominal aorta. 
locations in elastic arteries, it is rare for a Marfan patient to present with an aneurysm of the abdominal aorta. ${ }^{4}$ Massumi et al reviewed reports published before $1967 .^{8}$ They found 19 cases of abdominal aortic aneurysms in patients with Marfan's syndrome, nine of whom presented with an isolated aneurysm. Since 196712 patients with an abdominal aortic aneurysm have been described..$^{9-20}$ In some cases the aneurysm developed after resection of an ascending aortic aneurysm. ${ }^{10-13}$

Since the probability of rupture is high for patients with Marfan's syndrome, ${ }^{14}$ immediate operation is recommended. Treatment of an abdominal aortic aneurysm before rupture is relatively simple. In the present patient a woven Dacron tubular aortic graft was used. Careful handling of the friable tissues is important. Some recommend reinforcement of the suture line with Teflon pledgets. ${ }^{10}$

In the present case the operation was successful and the patient had no complaints four months later. However, the follow up procedure was inadequate because it did not include echocardiography of the aortic root. ${ }^{8}$ She died of a dissecting thoracic aneurysm five months after operation. This case underlines the fact that Marfan's syndrome is invariably progressive. The nature of the biochemical defect in the connective tissue leads to other cardiovascular abnormalities. In his series Crawford found that $50 \%$ of Marfan patients required another operation within one to ten years. ${ }^{9}$ Because cardiovascular abnormalities are difficult to detect with routine auscultation, phonocardiography, and chest $x$ rays, ${ }^{8}$ patients must be screened, at least every four to six months, by means of cross sectional echocardiography with special attention directed toward the aortic root. ${ }^{101121-23}$ R E Pyeritz (1987, personal communication) makes a total aortic magnetic resonance scan of each new patient and scans again at regular intervals after surgical replacement of the ascending aorta.

A dilated aorta is subject to dissection. ${ }^{2224}$ The relative risks of dissection and rupture, as indicated by the aortic diameter, are not known precisely ${ }^{25}$; in fact dissection may occur in a previously normal aorta. ${ }^{7}$ Histologically obvious tears have been found in the ascending aorta just above the aortic valves, as in our patient.

Until recently the prognosis for patients with Marfan's syndrome was poor. The hazards of surgical treatment are considerable. The encouraging results reported in the past few years justify a more vigorous surgical approach. ${ }^{911}$ Therefore, thorough evaluation and follow up of patients with Marfan's syndrome are needed. Operation is the only way to improve their life expectancy.

\section{References}

1 Eldridge R. The metacarpal index: a useful aid in the diagnosis of the Marfan syndrome. Arch Intern Med 1964;113:248-54.

2 Cross HE, Jensen AD. Ocular manifestations in the Marfan syndrome and homocystinuria. Am J Ophthalmol 1973;75:405-20.

3 McKusick VA. The cardiovascular aspects of Marfan's syndrome: a heritable disorder of connective tissue. Circulation 1955;11:321-42.

4 Murdoch JL, Walker BA, Halpern BL, Kuzma JW, McKusick VA. Life expectancy and causes of death in the Marfan syndrome. $N$ Engl $J$ Med 1972;286:804-8.

5 Pyeritz RE, McKusick VA. The Marfan syndrome: diagnosis and management. $N$ Engl $J$ Med 1979;300:772-7.

6 Phoniphutkul C, Rosenthal A, Nadas AS. Cardiac manifestations of Marfan's syndrome in infancy and childhood. Circulation 1973;47:587-96.

7 Roberts WC, Honig HS. The spectrum of cardiovascular disease in the Marfan syndrome: a clinicopathologic study of 18 necropsy patients and comparison to 151 previously reported necropsy patients. Am Heart J 1982;104:115-35.

8 Massumi RA, Lawer EW, Mizanich LF, Just H, Tawakkal P. Multiple aortic aneurysms (thoracic and abdominal) in twins with Marfan's syndrome: fatal rupture during pregnancy. $J$ Thorac Cardiovasc Surg 1967;53:223-30.

9 Crawford ES. Marfan's syndrome. Broad spectral surgical treatment cardiovascular manifestations. Ann Surg 1983;198:487-504.

10 Mohr R, Adar R, Rubinstein Z. Multiple aortic aneurysms in Marfan's syndrome. J Cardiovasc Surg (Torino) 1984;25:566-70.

11 Donaldson RM, Olsen EGJ, Emanuel RW, Ross DN. Management of cardiovascular complications in Marfan syndrome. Lancet 1980;iv:1178-81.

12 Miller DC, Stiuzan EB, Oyen PE, et al. Congenital resection of ascending aortic aneurysm and replacement of aortic valve. $J$ Thorac Cardiovasc Surg 1980;79:388-401.

13 Kazui T. Surgical treatment of expanding aneurysm of the abdominal aorta and annuloaortic ectasia in Marfan's syndrome. Kyobu Geka 1980;8:619-23.

14 Hepp W, Bercher M. Marfan-syndrom und aneurysma der aorta abdominalis. Vasa 1981;10:53-7.

15 Yu SC. Marfan's syndrome associated with spontaneous pneumothorax and abdominal aortic aneurysm. Int Surg 1976;61:30-1.

16 Houston HE. Abdominal aortic aneurysm in Marfan's syndrome. J Ky Med Assoc 1978;76:492-3.

17 Iguro $\mathrm{T}$, Kazui $\mathrm{T}$, Harada $\mathrm{H}$, et al. A surgical case of expanding aneurysm of the abdominal aorta in Marfan's syndrome. Kyobu Geka 1981;34:642-5.

18 Huang PJ, Chu SH, Lee YH, Chen WY, Wu TL. Abdominal aortic aneurysm in Marfan's syndromea case report. Taiwan I Hsueh Hui Tsa Chih 1983;82:868-73. 
19 Tsuchiya K, Hachida M, Seino R, Iida Y. Surgical treatment of annulo-aortic ectasia and aneurysm of the abdominal aorta in Marfan's syndrome. Kyobu Geka 1984;37:1012-6.

20 Funami $M$, Takaba $T$, Wakanabe $T$, et al. A surgical case of ruptured abdominal aortic aneurysm in Marfan's syndrome. Kyobu Geka 1985;38:558-62.

21 Bruno L, Tredici S, Mangiavacchi $M$, Colombo V, Mazzotta GF, Sirtori CR. Cardiac, skeletal, and ocular abnormalities in patients with Marfan's syndrome and in their relatives. Comparison with the cardiac abnormalities in patients with kyphoscoliosis. $\mathrm{Br}$ Heart J 1984;51:220-30.

22 Draulans-Noe HAY, Voogd PJ, Van de Kamp JJP,
Rohmer J. Cardiovasculaire afwijkingen bij het syndroom van Marfan: een echocardiografisch onderzoek. Ned Tijdschr Geneeskd 1985;129:688-93.

23 De Maria AN, Bamen W, Neuman A, et al. Identification and localisation of an aneurysm of the ascending aorta by cross sectional echocardiography. Circulation 1979;59:755-61.

24 Hirst AE, John VJ, Kine SW. Dissecting aneurysm of the aorta; a review of 505 cases. Medicine (Baltimore) 1958;37:217-79.

25 Pyeritz RE, Gott VL, McDonald GR, et al. Surgical repair of the Marfan aorta: technique, indications and complications. Johns Hopkins Med J 1982;151: 71-82. 